\title{
Article \\ Unilateral or Reciprocal Climate Policy? Experimental Evidence from China
}

\author{
Thomas Bernauer ${ }^{1, *}$, Liang Dong ${ }^{2}$, Liam F. McGrath ${ }^{1}$, Irina Shaymerdenova ${ }^{1}$ and Haibin Zhang ${ }^{3}$ \\ ${ }^{1}$ ETH Zürich, Center for Comparative and International Studies, 8092 Zürich, Switzerland; E-Mails: thbe0520@ethz.ch \\ (T.B.), liam.mcgrath@ir.gess.ethz.ch (L.F.M.), i.shaymerdenova@gmail.com (I.S.) \\ ${ }^{2}$ China Foreign Affairs University, Institute of Asian Studies, Beijing, China; E-Mail: dongliang@cfau.edu.cn \\ ${ }^{3}$ Peking University, School of International Studies, Beijing, China; E-Mail: zhanghb@pku.edu.cn \\ * Corresponding author
}

Submitted: 19 April 2016 | Accepted: 7 July 2016 | Published: 8 September 2016

\begin{abstract}
The traditional political economy account of global climate change governance directs our attention to fundamental collective action problems associated with global public goods provision, resulting from positive or negative externalities as well as freeriding. The governance architecture of the 1997 Kyoto Protocol uses the traditional approaches of international diplomacy for addressing such challenges: legally binding commitments based on principles of reciprocity and (fair) cost/burden sharing via formalized carbon-budgeting. Yet, the 2015 Paris Agreement has essentially abandoned this approach, as it now operates on the basis of internationally coordinated and monitored unilateralism. On the presumption that public opinion matters for government policy, we examine how citizens view this shift in climate policy from reciprocity to unilateralism, after many years of exposure to strong reciprocity rhetoric by governments and stakeholders. To that end, we fielded a survey experiment in China, the world's largest greenhouse gas (GHG) emitter. The results show that there is, perhaps surprisingly, strong and robust public support for unilateral, non-reciprocal climate policy. To the extent China is interested in pushing ahead with ambitious and thus costly GHG reduction policies, our results suggest that China can leverage segments of public support in order to overcome domestic obstacles to GHG mitigation policies.
\end{abstract}

\section{Keywords}

China; climate policy; reciprocity; unilateralism

\section{Issue}

This article is part of the issue "Climate Governance and the Paris Agreement", edited by Jon Hovi and Tora Skodvin (University of Oslo, Norway).

(C) 2016 by the authors; licensee Cogitatio (Lisbon, Portugal). This article is licensed under a Creative Commons Attribution 4.0 International License (CC BY).

\section{Introduction}

Most global governance efforts take the form of government representatives negotiating an international agreement that specifies the rights and obligations of participating countries. Such agreements are then taken back home and, depending on the characteristics of the agreement and national political institutions, are then subject to approval (or ratification) by government and/or the legislature before being implemented.
The 1992 UNFCCC and its 1997 Kyoto Protocol, which are at the center of the global climate governance system, follow exactly that approach. Yet, efforts to negotiate a successor agreement to the Kyoto Protocol, which ended in 2012, failed and the more than 190 countries involved opted for a radical departure from the hitherto practiced governance approach: through the 2015 Paris Agreement they moved away from legally binding emissions targets, set at the global level, and opted for a much more flexible system. This new 
system bundles unilateral promises by individual countries to engage in greenhouse gas (GHG) emission reductions. In the jargon of the UNFCCC these promises, which are voluntary and not legally binding, are called INDC, Intended Nationally Determined Contribution.

The Kyoto Protocol approach was motivated by a global public goods logic. Greenhouse gases (GHG) emitted by human or other (e.g. volcanic) activity accumulate in the atmosphere, no matter from where they originate. They then affect all countries via implications for temperature and the hydrological cycle, albeit to different degrees. These geo-physical properties and the associated structure of the collective action problem imply that, in principle, international collaboration is made difficult by positive and negative externalities problems. Reducing GHG emissions in a given country benefits that country in the medium to long term by reducing climatic risks, but also benefits all other countries in that respect. This means that there is a positive externality problem. Since virtually all countries and their political leaders tend to put national benefits (interests) first, positive externalities discourage contributions (GHG emission reductions) to the global public good of climate risk mitigation. Conversely, countries that do not reduce their emissions create additional climatic risks not only for themselves, but also offload parts of those risks or costs on other countries (negative externality). Yet, such countries can still benefit from GHG reductions by other countries. This means that they can freeride on the efforts of others.

Strong concerns over externality and freeriding problems, which can be found in many international policy areas, such as arms control, trade, finance, and the environment, tend to push global governance efforts towards agreements based on legally binding, reciprocal commitments that are subject to monitoring (verification) and to some form of decentralized enforcement. That is, countries tend to contribute in costly ways to such governance efforts only if other countries are equally (legally) committed and bound to do their "fair share". A large body of academic literature shows that reciprocity is required for cooperation in many different types of social, economic, and political settings, from the micro- to the global level (Falk \& Fischbacher, 2006; Fehr \& Gächter, 2000; Fehr, Gächter, \& Kirchsteiger, 1997; Milinski, Semmann, Krambeck, \& Marotzke, 2006).

The 2015 Paris Agreement departs from the idea of a global climate governance architecture based on jointly agreed, legally binding reciprocal commitments. It compiles unilateral, voluntary pledges (INDCs) of individual governments and subjects them to a review process, without any formal penalties (sanctions) for non-compliance. This new climate governance system still has some elements of reciprocity. Presumably, the idea is to "cycle" through repeated rounds of INDCs and their reviews. Each country can then decide (on its own) whether it wants to raise or lower the ambition level of past and upcoming pledges, contingent on whether other countries have actually implemented their previous pledges, and what their INDC for the coming years looks like.

Despite these elements of informal or vague reciprocity, the Paris Agreement approach is primarily a system of internationally coordinated unilateralism. One key issue in this context is how far, in terms of trying to meet the 1.5 or 2 degrees Celsius target, governments will be willing and able to take this approach, particularly in view of two types of uncertainty: first, uncertainty about the extent to which other countries will implement their INDCs (the traditional reciprocity and freerider problem); second, uncertainty about the extent to which the pledging country itself will be able to implement its INDCs in view of domestic political, economic, and technical obstacles.

In this paper, we examine the latter issue (domestic uncertainty and constraints) from a public opinion perspective, with an empirical focus on China. Public opinion has previously been shown to affect government policy choices in other countries (Burstein, 2003, 2014; Guisinger, 2009; Hicks, Milner, \& Tingley, 2014; Hornbeck, 2008; Kono, 2008; Mansfield \& Milner, 2012; Shapiro, 2011; Stimson, MacKuen, \& Erikson, 1995; Urbatsch, 2013; Wlezien, 1995). However the political system of China tends to make political decisionmakers somewhat less sensitive to public demands, in a median-voter model sense. Nevertheless, previous research shows that Chinese leaders are in fact quite responsive to public demands, particularly in the area of environmental policy (Johnson, 2010; Yang, 2005). While the presumption that the government of China is influencing or even shaping public opinion is quite plausible (but not empirically demonstrated), it is also plausible to assume that public opinion has some effect on what the government does in climate policy and other domains, given the research noted previously.

Analysis of public opinion on climate policy in China can thus serve two purposes: first, to understand potential limitations of unilateral climate policy emanating from constraints imposed on decision-makers by mass public opinion; second, to understand whether the departure from international reciprocity and the shift towards unilateralism, after years of strong reciprocity rhetoric by policy-makers, lines up with or conflicts with the views of citizens. The latter purpose is important, no matter whether mass public opinion in fact has an influence on government policy choices, and whether the government shapes public opinion, rather than public opinion shaping government policies, or vice versa. Moreover, in practical terms, understanding public opinion on this issue in China is relevant also because China accounts for $11 \%$ of total historical $\mathrm{CO}_{2}$ emissions since 1850 , and $30 \%$ of global emissions in 2014 (PBL Netherlands Environmental As- 
sessment Agency, 2015; World Resources Institute, 2013).

To shed light on the extent to which the public in China supports unilateral climate policy we use two experiments embedded in a survey using an online convenience sample. In one experiment we randomly assigned different frames to an item measuring respondents' attitudes towards reciprocal vs unilateral climate policy. In the other experiment we primed respondents with positive or negative information about the climate policies of other countries. Overall, we find surprisingly robust support for unilateral climate policy in China within our sample, reinforcing previous surveys that find the Chinese population believes China has a responsibility to take unilateral steps against climate change (World Bank, 2010). This leaves some room for optimism about Chinese policy-makers being willing and able, despite strong countervailing pressure by polluting industries, which tend to demand "softer" policies justified by international level playing field and cost arguments, to set up ambitious INDCs and effectively implement them.

\section{Argument}

Ever since negotiations on a global climate governance system began in the early 1990s, government representatives have demanded reciprocity, in the sense of requesting a "fair" contribution from each country involved. The 1997 Kyoto Protocol with its formal reduction targets and monitoring mechanism reflects these demands. This rhetoric and its legal and organizational reflection in the UNFCCC and Kyoto Protocol process is somewhat at odds with the many local, national, and regional climate policy initiatives, which are predominantly non-reciprocal, that is unilateral and not explicitly contingent on what other political units (notably, countries) do. Moreover, information from the very few surveys that have examined citizens' attitudes towards unilateral vs reciprocal climate policy (Bernauer \& Gampfer, 2015; World Bank, 2010) observe rather high levels of support for unilateral climate policy.

Have governments actually missed out on opportunities to install more ambitious climate policies unilaterally, while global climate negotiations were stalling over the past $10-15$ years, due to polluting industry pressure or other reasons (e.g. ignorance of governments about citizens' attitudes)? Or is there something wrong with survey measurement instruments that made them overstate public support for unilateral climate policy, due to social desirability bias or other factors?

Using a framing experiment embedded in a population based survey in the United States and India, Bernauer and Gampfer (2015) found that mass public support for unilateral climate policy was stronger than expected. Or, conversely, citizens appear to be surprisingly non-reciprocal, relative to what government rhetoric in climate negotiations would suggest. The study also shows that strong support for unilateral climate policy, which is incompatible with standard theory on global public goods, is not the result of citizens being poorly informed about climate policy and its cost implications, which might lead to inflated support due to social desirability bias in survey responses. We build on that work, add another experiment, and focus on China, for which there is very little information on public opinion concerning climate change and climate change policy.

The arguments to be tested in our two experiments center on how strong public support for unilateral climate policy actually is, and whether it is susceptible to framing and priming effects. In the first experiment, we expect information about ambitious GHG mitigation measures in other key countries to increase support for unilateral climate policy, and information about nonambitious measures in other key countries to have a negative effect. Taken together, the two experiments provide insights into how strong public support for unilateral climate policy in China is. In the second experiment, we expect support for unilateral climate policy to increase with positive frames: co-benefits, such as green jobs and technological innovation, effectiveness of unilateral policies in helping to solve the climate change problem, adaptation focus of climate policy, safeguards provisions for responding to "abstinence" or "free-riding" of other countries, leading by example (positive diffusion effect), and demonstrating global leadership. Conversely, we expect negative frames to reduce support for unilateral climate policy: high costs, freeriding by others, and mitigation (as opposed to adaptation measures).

\section{China's Climate Policy}

Before turning to the experimental design, we provide a very brief summary of China's climate change policy in order to contextualize our study and its results. In particular, we focus on how China's climate policy relates to its participation in international climate negotiations.

Within global climate change negotiations China has long taken the position that any international climate agreement should be based on the principles of historical and differentiated responsibility. In this context China considers itself to be a developing country (Pan, Chen, Zhang, Bao, \& Zhang, 2015; Xie, 2010). Therefore, it has taken the position that it should incur less of the burden for climate change mitigation, compared to developed countries with long histories of large-scale GHG emissions. Nevertheless, maintaining such a position has turned out to be more difficult in recent years, as China has become the second largest economy in the world and the world's largest (current) GHG emitter (http:// www.wri.org/publication/assessing-implementation-chi nas-climate-policies-12th-5-year-period). 
Furthermore, a key stance in China's international climate policy position has been opposition to accepting internationally set and legally binding GHG reduction obligations. Although China has often called on developed countries to agree to legally binding commitments to reduce GHG emissions and provide financial support for developing countries, it has argued that developing countries' efforts to deal with climate change should be voluntary and reflect current capacity (Xie, 2010; Zhang, 2013). As China considers itself a developing country in this case, it has been unwilling to accept legally binding commitments through international negotiations.

Even though China has long opposed mandatory international GHG emissions targets for developing countries, including China, it has in recent years made important pledges and has adopted substantial measures to unilaterally tackle climate change. Most notably, in 2015 the Chinese government announced that it plans to reduce $\mathrm{CO}_{2}$ emissions per unit of GDP by $60-65 \%$ over the period of 2005 to 2030 (Climate Action Tracker, 2014; Energy Research Institute 2015; Green \& Stern, 2015). This pledge has been coupled with large investments into energy production from renewables (Energy Research Institute, 2015; World Resources Institute, 2015).

\section{Study Design}

\subsection{Sampling}

We recruited 1067 participants through social media networks, including WeChat (Weixin in Mandarin) and Sina Weibo. WeChat is a mobile text and voice messaging and communication service developed by Tencent. ${ }^{1}$ Sina Weibo is a Chinese microblogging (weibo) website developed by SINA Corporation. ${ }^{2}$ It is somewhat similar to Twitter or Facebook. While our sample is a convenience sample, this does not affect the internal validity of our estimated treatment effects, in which we are interested in this paper. However, it does mean that we cannot generalize the description of attitudes and treatment effects to the general Chinese population.

The socio-demographics of our sample are shown in the Appendix 1. These statistics show that our sample is younger and better educated, relative to the overall distribution in China. For example, approximately $60 \%$ of our sample is aged between 20 and 30, compared to approximately $9 \%$ of the population (ClA, 2016). Approximately $90 \%$ is currently attending university or has a university degree, compared to $17.95 \%$ of people aged 25-34 in the population (OECD, 2016). Our survey can thus be regarded as some form of elite survey.

While this sample bias and the opt-in approach to

\footnotetext{
${ }^{1}$ https://web.wechat.com

${ }^{2}$ http://weibo.com
}

sampling does not allow for representative inferences about what the Chinese populations' attitudes are, this limitation is not relevant in our case, because it still allows us to identify average treatment effects within our sample. In addition, it offers insights into the attitudes and preferences of relatively well-educated Chinese citizens, whose opinions are more likely to affect policy-making than opinions among less educated parts of the population.

\subsection{Survey Instrument and Embedded Experiments}

The survey ${ }^{3}$ into which the experiments were embedded has the following structure:

1. Socio-Demographic items

2. Items about interest and belief in global warming/climate change

3. Survey experiment 1

4. Items for the outcome measures for experiment 1

5. Survey experiment 2

6 . Items for the outcome measures for experiment 2

The first experiment exposed respondents to information about ambitious or non-ambitious GHG mitigation policies of other countries that are, from the viewpoint of their emissions, important to the longterm success of global climate risk mitigation, notably the United States, the European Union (EU), and India. Participants were randomly assigned to one of the 6 treatments (i.e., short pieces of information) shown in Table 1, which comes in the form of a piece of text before moving on to the outcome questions. We designed the treatment texts so that they include information on pledges to reduce GHG emissions (which correspond to pledges the respective country [or EU] has actually made), and also (fictional) information on what (unnamed) experts think about the respective pledge, in terms of it being fair and corresponding to the respective country's (or EU) capability and responsibility. This treatment design makes the treatments as homogenous as possible in terms of their structure (though not content in terms of negative or positive priming).

After randomly assigned exposure to one of the treatments (or control) shown in Table 1, we measured each respondent's attitudes towards China's climate policy, based on a wide range of survey items. These are displayed in Table 2. In order to avoid social desirability bias, we emphasize cost implications at the national and individual level in many of the listed survey items.

\footnotetext{
3 The survey instrument in Mandarin is available from the authors on request.
} 
Table 1. Treatment conditions for experiment $1 .{ }^{4}$

USA Positive The United States has promised that it will reduce its greenhouse gas emissions by $14-17 \%$ below 1990 levels by 2025. Most experts think this is a fair contribution by the United States to reducing greenhouse gas emissions worldwide, since it reflects the United States' capability and responsibility.

USA Negative The United States has promised that it will reduce its greenhouse gas emissions by $14-17 \%$ below 1990 levels by 2025. Most experts think this is not a fair contribution by the United States to reducing greenhouse gas emissions worldwide, since it does not reflect the United States' capability and responsibility.

India Positive India has promised that it will reduce the greenhouse gas emissions intensity of its GDP by 20$25 \%$ by 2020 compared to 2005 levels. Most experts think this is a fair contribution by India to reducing greenhouse gas emissions worldwide, since it reflects India's capability and responsibility.

India Negative India has promised that it will reduce the greenhouse gas emissions intensity of its GDP by 20$25 \%$ by 2020 compared to 2005 levels. Most experts think this is not a fair contribution by India to reducing greenhouse gas emissions worldwide, since it does not reflect India's capability and responsibility

\begin{tabular}{|c|c|}
\hline EU Positive & $\begin{array}{l}\text { The European Union has promised that it will reduce its greenhouse gas emissions by } 40 \% \text { below } \\
1990 \text { levels by } 2030 \text {. Most experts think this is a fair contribution by the European Union to } \\
\text { reducing greenhouse gas emissions worldwide, since it reflects the European Union' capability } \\
\text { and responsibility. }\end{array}$ \\
\hline
\end{tabular}

EU Negative $\quad$ The European Union has promised that it will reduce its greenhouse gas emissions by $40 \%$ below 1990 levels by 2030. Most experts think this is not a fair contribution by the European Union to reducing greenhouse gas emissions worldwide, since it does not reflect the European Union' capability and responsibility.

Control group (no information treatment)

Table 2. Attitudes towards climate policy.

People hold different views about whether China should give 1 Should give priority to measures against global priority to measures against global warming, even if such measures have a negative effect on the Chinese economy. What is your view? warming 2 Should not give priority to measures against global warming 3 Don't know

To deal with global warming, do you think China is doing... 1 Too much

2 About the right amount

3 Not enough

4 Don't know

Do you favor or oppose preserving or expanding forested areas in China, even if this means less land for agriculture or construction in China?
1 Favor strongly

2 Favor somewhat

3 Oppose somewhat

4 Oppose strongly

5 Don't know

1 Favor strongly

2 Favor somewhat

3 Oppose somewhat

4 Oppose strongly

5 Don't know

\footnotetext{
${ }^{4}$ We provide the English translation here.
} 
Imagine that if China took effective steps against global warming, this would increase electricity costs to the average household in China by 30 RMB per month. Would you be willing or not be willing to pay this additional cost as part of taking steps against global warming?

Could you please tell us to what extent you personally agree or disagree with the following statements?

If I had to reduce my energy consumption and carbon dioxide
emissions this would reduce my quality of life too much.

If I avoid activities that emit carbon dioxide I contribute to
solving the problem of global warming.
solving the problem of global warming.
1 Would be willing
2 Would not be willing
3 Don't know

\begin{tabular}{|c|c|}
\hline & $\begin{array}{l}3 \text { Mostly disagree } \\
4 \text { Strongly disagree }\end{array}$ \\
\hline $\begin{array}{l}\text { I prefer to enjoy life without having to worry about how } \\
\text { much energy I consume and how much carbon dioxide I emit. }\end{array}$ & $\begin{array}{l}1 \text { Strongly agree } \\
2 \text { Mostly agree } \\
3 \text { Mostly disagree } \\
4 \text { Strongly disagree }\end{array}$ \\
\hline $\begin{array}{l}\text { Imagine you were buying a car and you had to choose } \\
\text { between a larger, more powerful car that consumes more } \\
\text { fuel, and a smaller and less powerful car that consumes less } \\
\text { fuel. Assume that this would be the only car you own, and } \\
\text { that both the large and the small car cost exactly the same. } \\
\text { Which car would you buy? }\end{array}$ & $\begin{array}{l}1 \text { Larger, more powerful car consuming more fuel } \\
2 \text { Smaller, less powerful car consuming less fuel }\end{array}$ \\
\hline $\begin{array}{l}\text { Which of the following statements comes closest to your own } \\
\text { point of view? China should reduce its carbon dioxide } \\
\text { emissions... }\end{array}$ & $\begin{array}{l}1 \text { regardless of what other countries do } \\
2 \text { only if industrialized countries (such as the United } \\
\text { States, Germany, Japan) reduce their emissions } \\
3 \text { only if industrialized countries (such as the United } \\
\text { States, Germany, Japan) as well as developing } \\
\text { countries (such as India, Brazil) reduce their } \\
\text { emissions } \\
4 \text { China should not reduce its carbon dioxide } \\
\text { emissions }\end{array}$ \\
\hline
\end{tabular}

1 Strongly agree

2 Mostly agree

3 Mostly disagree

4 Strongly disagree

1 Strongly agree

2 Mostly agree

Mostly disagree

gly disagree

\begin{abstract}
I prefer to enjoy life without having to worry about how much energy I consume and how much carbon dioxide I emit.

Imagine you were buying a car and you had to choose between a larger, more powerful car that consumes more fuel, and a smaller and less powerful car that consumes less fuel. Assume that this would be the only car you own, and that both the large and the small car cost exactly the same. chich car would you buy?
\end{abstract}

To minimize measurement errors, and because it seems impossible to capture preferences concerning climate policy with one single survey item, we aggregated the answers to these 10 survey items into a single scale using Bayesian ordinal factor analysis. The posterior median of the latent variable is used as the outcome measure for each respondent. This dependent variable is standardized to have a mean of zero and standard deviation equal to one, for ease of interpretation. In the analysis that follows we only include respondents who answered all of these 10 questions in the survey. This leaves 758 respondents for the statistical analysis, with similar numbers of respondents in each treatment condition.

The second experiment is a framing experiment, where the frame (a piece of text) is inserted into a baseline survey item. This baseline item asks respondents whether they believe China should reduce its carbon dioxide emissions (identical to the final question used for the first experiment):

- regardless what other countries do

- only if industrialized countries (such as the United States, Germany, Japan) reduce their emissions

- only if industrialized countries (such as the United States, Germany, Japan) as well as developing countries (such as India, Brazil) reduce their emissions

"China should not reduce its carbon dioxide emissions" was also added as a response category to take care of the possibility that some respondents may prefer China not to reduce its emissions, no matter what 
other countries do. 35 respondents did not answer this question, leaving 1032 respondents for the statistical analysis.

Survey participants were then randomly assigned to one of the following frames, with the baseline item (not including a frame) serving as the control group:

- Many experts argue, however, that emission reductions by China would be very costly and would hurt the Chinese economy. (Expected framing effect: negative)

- Many experts argue, however, that emission reductions by China could also contribute to technological innovation and create more jobs in China. (Expected framing effect: positive)

- Many experts argue, however, that reducing carbon dioxide emissions in China would also help reduce local air pollution, which is severe in many Chinese cities. (Expected framing effect: positive)

- Many experts argue, however, that emission reductions by China would motivate other countries to follow the Chinese example and reduce their emissions as well. (Expected framing effect: positive)

- Many experts argue, however, that emission reductions by China are required to demonstrate China's global political leadership. (Expected framing effect: positive)

- Many experts argue, however, that China is responsible for only around $29 \%$ of total carbon dioxide emissions worldwide. Hence they argue that the global warming problem cannot be solved if China reduces its emissions on its own, but other countries do not do the same. (Expected framing effect: negative)

- Many experts argue, however, that reducing carbon dioxide emissions is expensive. Therefore, if China reduces its emissions, but other countries do not,
Chinese businesses and their exports to other countries will become less competitive and jobs in China may be lost. (Expected framing effect: negative)

- At recent international climate conferences, the political leaders of industrialized countries have agreed to provide large amounts of funding and technology to facilitate the reduction of carbon dioxide emissions in developing countries, including China. (Expected framing effect: positive)

\section{Results}

\subsection{Experiment 1}

For experiment 1, which focuses on information about other countries mitigation efforts, we start by examining the distribution of the outcome measure (dependent variable) across each of the experimental conditions. The results show that the variance in support for climate policy, as captured by our composite measure based on 11 survey items, is similarly dispersed across all experimental conditions. However, the mean tends to be lower in the control group compared to the treatment conditions (see Figure 1).

We then estimated the average treatment effects using ordinary least squares regression. Figure 2 presents these treatment effects.

Surprisingly, the results show positive treatment effects for all treatment conditions. Thus any information about GHG reduction policy in other key countries, no matter whether positive or negative, tends to induce more climate policy support. However the $90 \%$ confidence intervals for these treatment effects do not include zero only for the United States treatments, when not including demographic controls, and for the positive United States treatment, when including demographic controls.

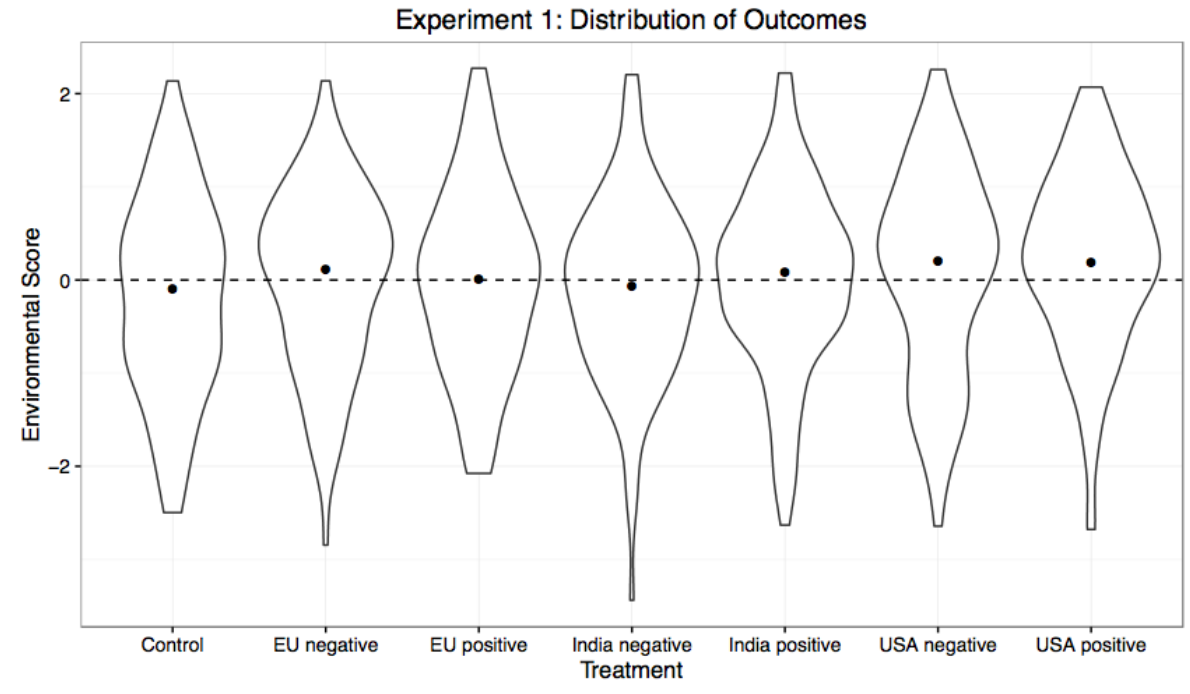

Figure 1. Distribution of outcome measure by treatment condition, experiment 1 . Notes: Points indicate the mean score on the outcome variable. The horizontal dashed line indicates the global mean. 


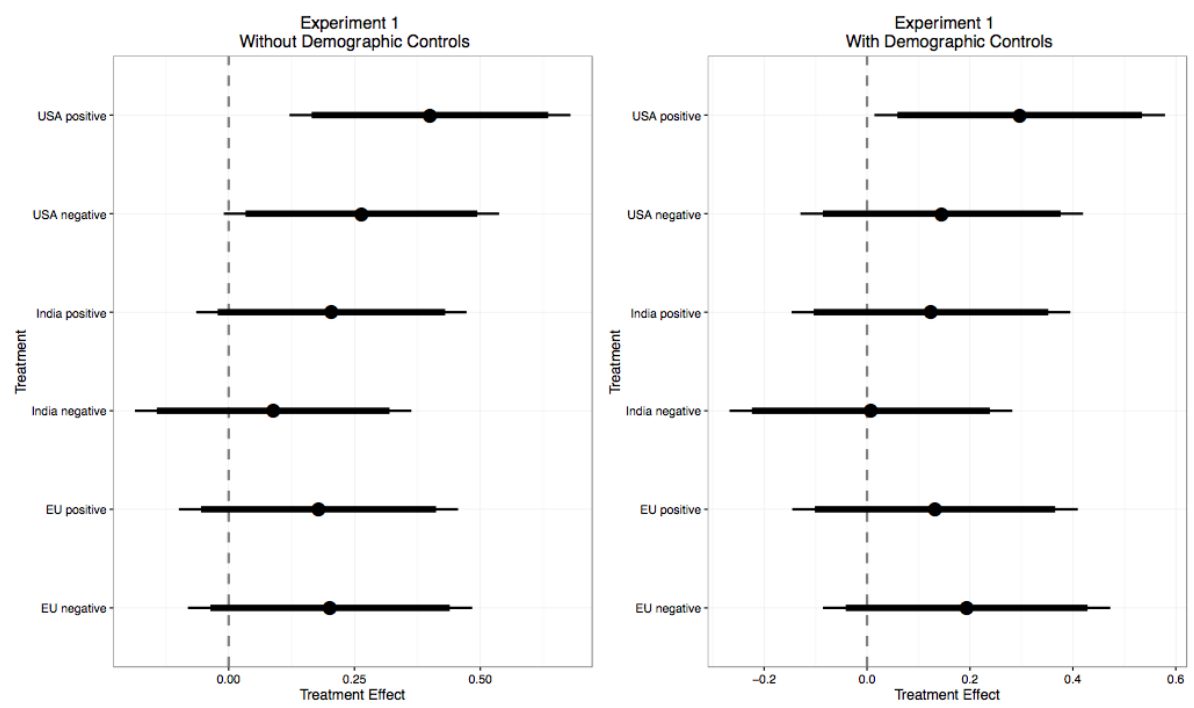

Figure 2. Estimated treatment effects, experiment 1. Note: The panel on the left shows the estimates without demographic controls, the panel on the right shows the estimates with demographic controls (age, region, education, profession, and gender). The bullet points on the wiskers indicate the average treatment effects. Broad horizontal wiskers indicate $90 \%$ and narrower wiskers $95 \%$ confidence intervals. If confidence intervals intersect with the dotted vertical line the estimated treatment effect is not statistically significant.

The direction of these results suggests that any information on emission reductions increases support climate policy in our sample. This is particularly the case for the United States treatments, where the negative information on climate policy by the United States has a similarly sized effect to that of the positive information concerning climate policy by India. One interpretation of this result is that respondents take the 14$17 \%$ GHG reductions noted in the US treatment condition to be, overall, a good thing, even though the treatment also states that experts consider the size of reduction not to be a fair contribution in view of US capacity and historical emissions.

Next we focus on the comparison between the positive and negative treatment effects for a given country. These results are more in line with our theoretical expectations. For both India and the United States, positive treatments are associated with more climate policy support than negative treatments. Yet, contrary to our expectations the difference in climate policy support between the positive and negative EU treatments is slightly negative.

While the effect of the positive treatment concerning the United States is statistically significantly different from the control group, we would like to compare also if it is statistically significantly different from the effect of the associated negative treatment. Therefore, in Figure 3 we plot the estimated differences between the positive and negative treatments, for each country/group of countries. This is the average treatment effect of having received a positive treatment relative to a negative treatment.

The results shown in Figure 3 indicate that the effect of receiving a positive treatment compared to a negative treatment is similarly positive when the reference country is the United States or India. These effects lead to an approximate increase of $15 \%$ of a standard deviation in climate policy support. In contrast, the effect of a positive treatment compared to a negative treatment when the reference countries are the EU, is very close to zero and in fact slightly negative. None of these differences in treatment effects are statistically significant at conventional levels, however.

\subsection{Experiment 2}

We now turn to experiment 2, which provides respondents' positive or negative views about reducing emissions without any information about other countries. Figure 4 displays the distribution of responses to the survey item that forms the basis of the second experiment.

Visual inspection of Figure 4 shows that the share of strong supporters of unilateral climate policy (the black parts of the bars) remains in the order of 50 $65 \%$. The distribution of responses in China is thus similar to those found for India by Bernauer and Gampfer (2015), with very low support for not reducing GHG emissions at all and similar levels of support for unilateral climate policy across treatment and control conditions. A key difference, however, is the nature of reciprocity preferences exhibited between the two samples. For instance, in Bernauer and Gampfer (2015), of those respondents from India who support climate policy only if other countries act as well, the vast majority are primarily concerned with whether industrialized countries reduce their GHG emissions too. In contrast, within the China sample, those respondents 


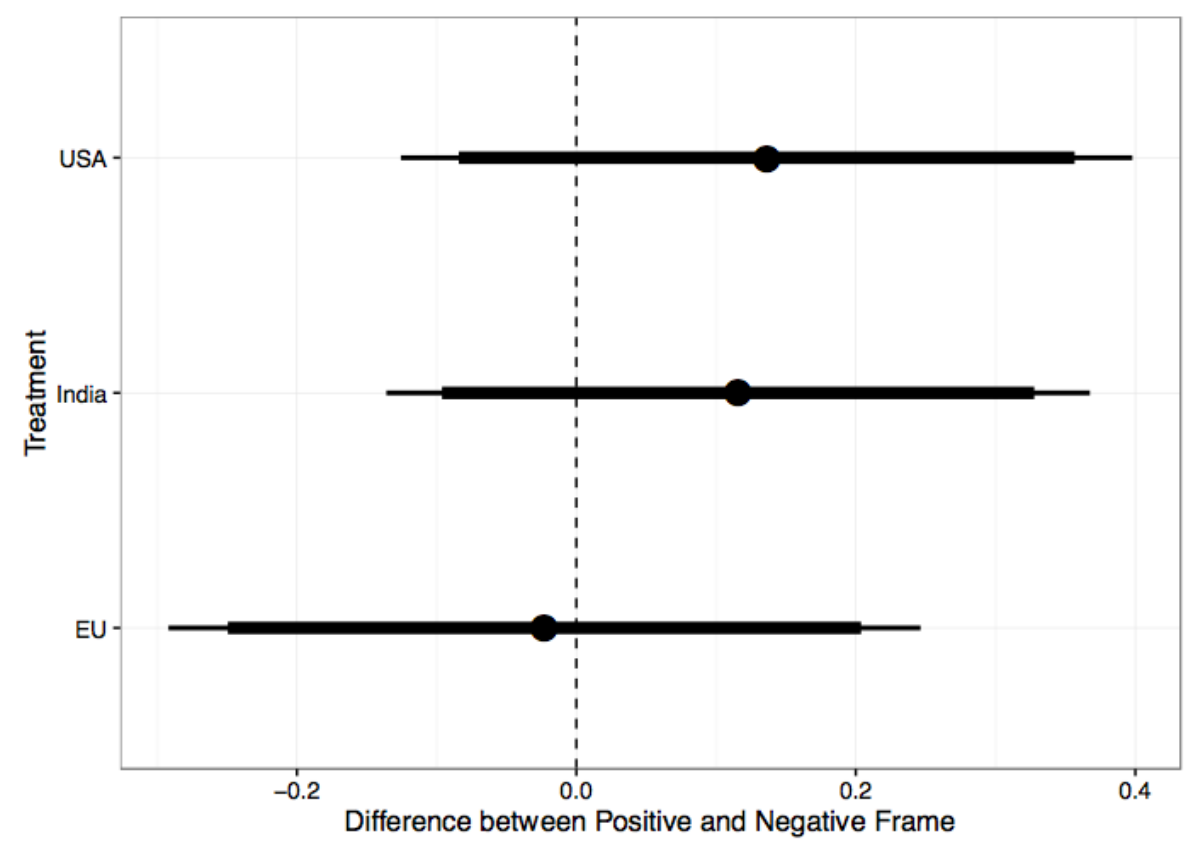

Figure 3. Estimated differences in climate policy support between positive and negative treatments for a given reference country/group of countries. Notes: see notes for Figure 2 on how to read and interpret Figure 3.

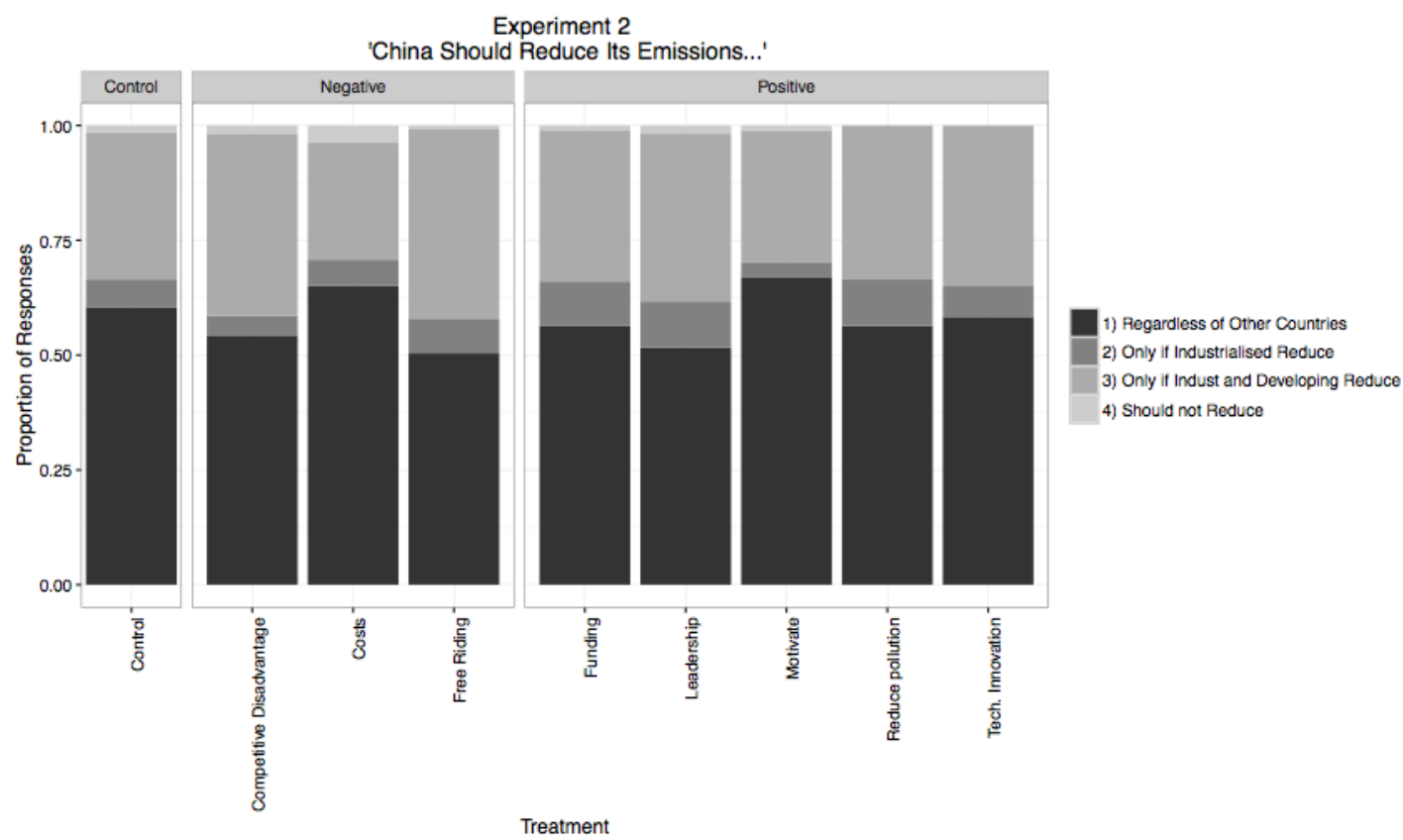

Figure 4. Distribution of responses, by treatment condition, in experiment 2.

focus on both the actions of industrialized and developing countries.

We again estimate average treatment effects for this outcome measure using ordinary least squares regression both with and without demographic controls. Thus for this present analysis we treat the ordinal dependent variable as if it were measured on the interval level. ${ }^{5}$ These estimates can be interpreted as how the mean re-

${ }^{5}$ Results are similar when using an ordinal logit estimator. The predicted probabilities generated from doing so are displayed in figure 6 of the appendix. sponse differs between a given treatment condition and the control group. Figure 5 displays the results.

The results shown in Figure 5 do not support the expectations outlined above. None of the frames are statistically significant at conventional levels. In terms of the direction of the treatment effect, for the five frames we expected to have a positive treatment effect (technological innovation, reducing pollution, motivating other countries, leadership, and improved funding prospects), only the motivation frame has a positive effect. The others have either very small negative effects that are close to zero, or in the case of leadership have 


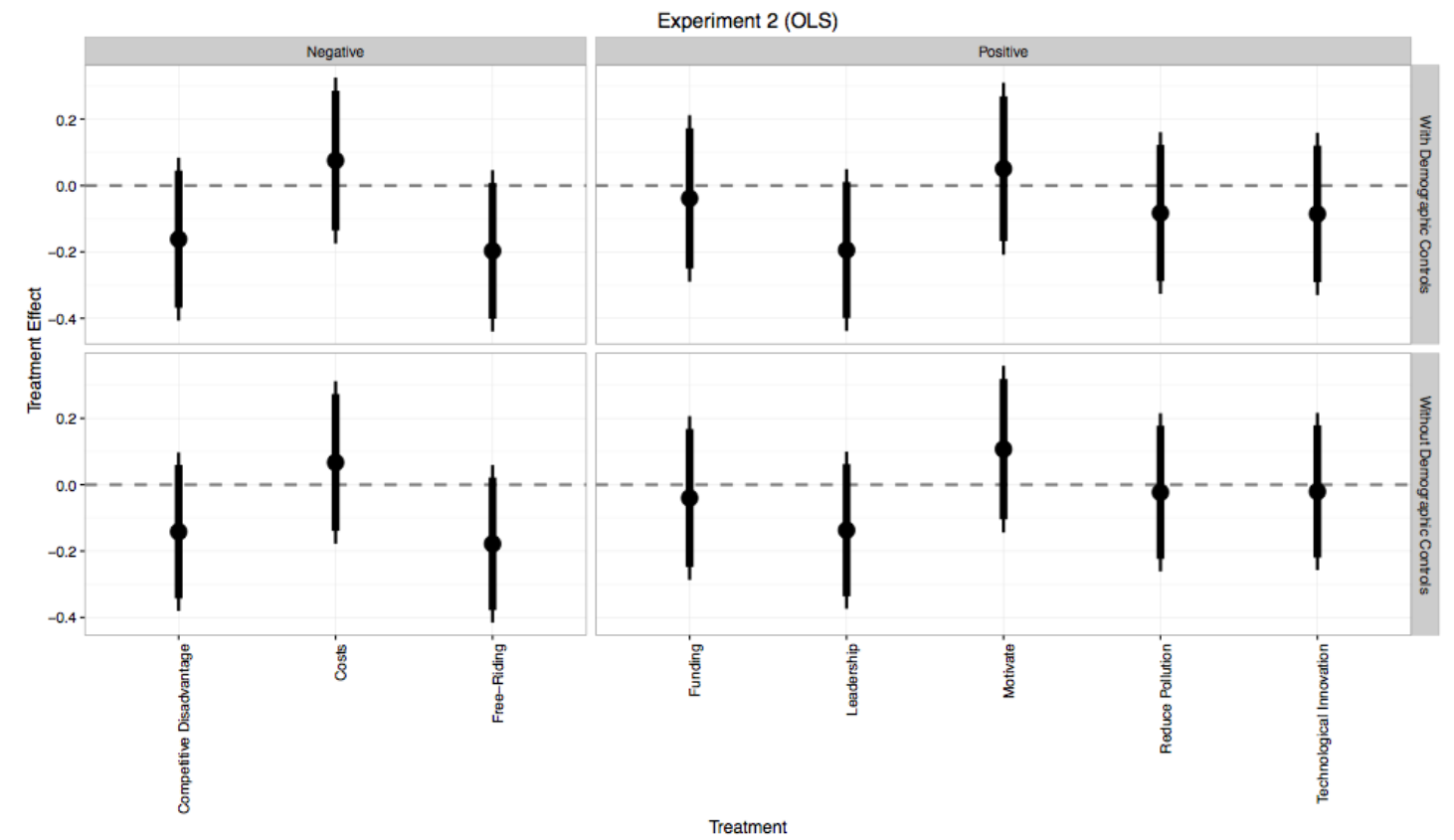

Figure 5. Estimated treatment effects, experiment 2. Notes: see notes for Figure 2 on how to read and interpret Figure 5. Treatment effects are grouped by whether we expected positive or negative effects, and whether demographic controls are included or not.

fairly strong negative effects. For those frames we expected to have negative treatment effects (free-riding, costs, and competitive disadvantage) two of the three do indeed have relatively strong negative effects on support for unilateral climate policy. However, the costs frame has a slightly positive effect, again running counter to our expectations.

In brief, support for unilateral climate policy, within our sample, is quite high and changes little across the particular frames we randomly allocated participants to.

\section{Discussion and Conclusion}

The main purpose of the research presented in this paper was to explore the extent to which citizens support what has recently become the new overall approach to global climate change governance, namely internationally coordinated unilateralism, in the form of INDCs. Conventional political economy accounts of global public goods provision as well as strong reciprocity rhetoric by most governments and stakeholders over the past two to three decades should make us skeptical about whether public support for unilateral climate policy lines up well with the recent shift in the global climate governance architecture. Moreover, even though existing survey data on unilateral climate policy preferences, which is very scarce, suggests rather high level of support, there is a possibility that measured support levels are inflated because of social desirability bias.

To assess how strong public support for unilateral climate policy really is we implemented a survey experiment in China, the world's largest GHG emitter. In experiment 1 we find that information treatments class- ing GHG emission reduction policies of the USA as positive have a statistically significant effect in increasing support for climate policies. However all of the treatment conditions, whether framing emission reductions in a positive or negative light, also lead higher average levels of support relative to the control group, although not statistically significantly so. In experiment 2 we find results similar to those for India in a recent publication by Bernauer and Gampfer (2015). Specifically, we observe high levels of support for unilateral climate policy in our Chinese sample, and very low levels of support for never reducing carbon dioxide emissions. In addition, we find that framing of GHG emission reductions in positive or negative lights does not significantly alter levels of support. In other words, we find that support for unilateral climate policy is rather strong and also robust, in the sense of not changing significantly even when participants are treated with information on positive or negative consequences of unilateral climate policy, or with negative news on GHG reduction policies of other key countries.

The main policy implication we can draw from this evidence is that, to the extent the Chinese government is interested in pushing ahead with ambitious and thus costly GHG reduction policies, it should be able to leverage segments of public support in order to overcome domestic obstacles to GHG mitigation policies.

We conclude with two caveats and options for further research. To start with, we opted for a convenience sampling approach because we were mainly interested in studying experimental treatment effects. However, it would also be useful to describe and explain unilateral or reciprocal climate policy preferences 
of the mass population in China. Related to that, it would be interesting to find out whether preferences differ between the country's elite (in terms of education levels and income) and the mass public, and if so why. Furthermore, the weak treatment effects found may be a result of ceiling effects due to our sample likely over representing individuals with strong prior support for climate policy. Another caveat is that limited knowledge of climate policy issues combined with the cost implications of ambitious climate policy being hard to anticipate might create a risk of social desirability bias and inflated levels of support for unilateral climate policy. We think that our experimental designs are able to deal with this challenge quite effectively. However, further research could make treatment conditions (e.g. those focusing on what other countries do) even more explicit and go further in increasing the personal stakes associated with responses (e.g. in terms of using substantive willingness to pay, rather than willingness to support measures).

These caveats notwithstanding, the research presented here offers interesting starting points for inquiries into the potential and limitations of non-reciprocal (i.e. unilateral) climate policy. At least for the time being, it appears unlikely that the global climate governance architecture will revert to a formalized, top-down target setting and cost- and burden-sharing approach. Because of that, it is important to understand how far citizens, who are asked to shoulder the costs of GHG reductions, are willing to accept costly unilateral climate policies.

\section{Acknowledgments}

The research for this article was financially supported by European Research Council (ERC) Advanced Grant no. 295456 (Sources of Legitimacy in Global Environmental Governance). The authors are grateful to Mike Hudecheck for excellent research assistance.

\section{Conflict of Interests}

The authors declare no conflict of interests.

\section{References}

Bernauer, T., \& Gampfer, R. (2015). How robust is public support for unilateral climate policy? Environmental Science and Policy, 54, 316-330.

Burstein, P. (2003). The impact of public opinion on public policy: A review and an agenda. Political Research Quarterly, 56(1), 29-40.

Burstein, P. (2014). American public opinion, advocacy, and policy in congress: What the public wants and what it gets. New York, NY: Cambridge University Press.

CIA. (2016). CIA world factbook: China. Retrieved from https://www.cia.gov/library/publications/the-worldfactbook/geos/ch.html

Climate Action Tracker. (2014). China. Retrieved from http://climateactiontracker.org/countries/china.html

Energy Research Institute. (2015). China 2050 high renewable energy penetration scenario and roadmap study. Retrieved from http://www.efchina.org/Repor ts-en/china-2050-high-renewable-energy-penetratio n-scenario-and-roadmap-study-en

Falk, A., \& Fischbacher, U. (2006). A theory of reciprocity. Games and Economic Behavior, 54, 293-315.

Fehr, E., \& Gächter, S. (2000). Fairness and retaliation: The economics of reciprocity. Journal of Economic Perspectives, 14, 159-181.

Fehr, E., Gächter, S., \& Kirchsteiger, G. (1997). Reciprocity as a contract enforcement device: Experimental evidence. Econometrica, 65, 833-860.

Green, F., \& Stern, N. (2015). China's "new normal": Structural change, better growth and peak emissions. London: Grantham Research Institute on Climate Change and the Environment.

Guisinger, A. (2009). Determining trade policy: Do voters hold politicians accountable? International Organization, 63(3), 533-557.

Hicks R., Milner, H. V., \& Tingley, T. (2014). Trade policy, economic interests, and party politics in a developing country: The political economy of CAFTA-DR. International Studies Quarterly, 58(1), 106-117.

Hornbeck, J. F. (2008). The Dominican Republic-Central America-United States free trade agreement (CAFTA$D R$ ). Washington, DC: Congressional Research Service.

Johnson, T. (2010). Environmentalism and NIMBYism in China: Promoting a rules-based approach to public participation. Environmental Politics, 19, 430-448.

Kono, D. Y. (2008). Does public opinion affect trade policy? Business and Politics, 10(2). doi:10.2202/14693569.1224

Mansfield, E. D., \& Milner, H. V. (2012). Votes, vetoes, and the political economy of international trade agreements. Princeton, NJ: Princeton University Press.

Milinski, M., Semmann, D., Krambeck, H.-J., \& Marotzke, J. (2006). Stabilizing the Earth's climate is not a losing game: Supporting evidence from public goods experiments. Proceedings of the National Academy of Sciences, 103, 3994-3998.

OECD. (2016). Population with tertiary education (indicator). Retrieved from https://data.oecd.org/eduatt/ population-with-tertiary-education.htm

Pan, J., Chen, Y., Zhang, H., Bao, M., \& Zhang, K. (2015). Strategic options to address climate change. In $\mathrm{D}$. Qin, Y. Ding, \& M. Mu (Eds.), Climate and environmental change in China: 1951-2012 (pp 129-137). Berlin Heidelberg: Springer-Verlag.

PBL Netherlands Environmental Assessment Agency. (2015). Emissions database for global atmospheric 
research (EDGAR). Retrieved from http://edgar.jrc. ec.europa.eu/news_docs/jrc-2015-trends-in-globalco2-emissions-2015-report-98184.pdf

Shapiro, R. Y. (2011). Public opinion and American democracy. Public Opinion Quarterly, 75(5), 982-1017.

Stimson, J. A., Mackuen, M. B., \& Erikson, R. S. (1995). Dynamic representation. American Political Science Review, 89(3), 543-565.

Urbatsch, R. (2013). A referendum on trade theory: Voting on free trade in Costa Rica. International Organization, 67(1), 197-214.

Wlezien, C. (1995). The public as thermostat: Dynamics of preferences for spending. American Journal of Political Science, 39(4), 981-1000.

World Bank. (2010). Public attitudes toward climate change: Findings from a multi-country poll. Washington, DC: World Bank.
World Resources Institute. (2013). CAIT 2.0. country GHG emissions. Washington DC: World Resources Institute.

World Resources Institute. (2015). Assessing implementation of China's climate policies in the 12th 5-year period. Washington DC: World Resources Institute.

Xie, Z. (2010). Speech at the high level segment of COP16 \& CMP6. UN Climate Change News Room. Retrieved from https://unfccc.int/files/meetings/cop_ 16/statements/application/pdf/101208_cop16_hls_c hina.pdf

Yang, G. (2005). Environmental NGOs and institutional dynamics in China. The China Quarterly, 181, 46-66.

Zhang, H. (2013). China and international climate change negotiations. WeltTrends Online Dossier. Retrieved from http://welttrends.de/res/uploads/Zhang_China -and-International-climate-change-negotiations.pdf

\section{About the Authors}
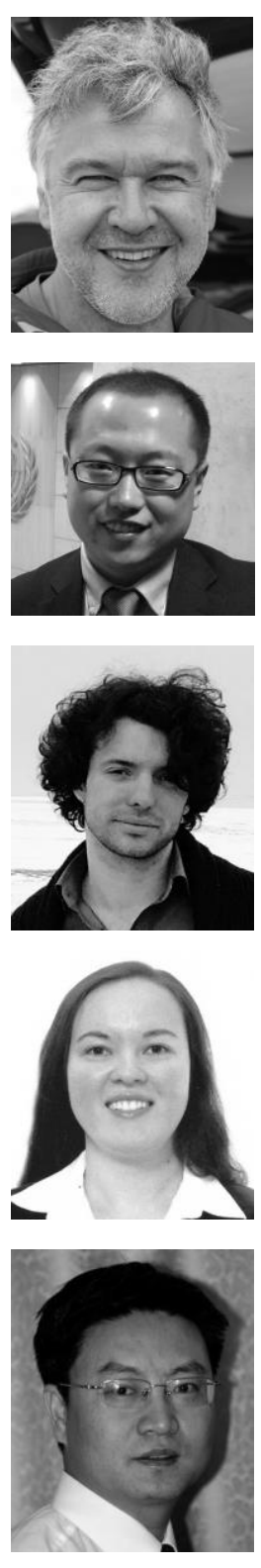

Haibin Zhang is Professor of the School of International Studies, Peking University, and Director of the Center for International Organization Studies, Peking University. He received his PhD. in 1998 from the School of International Studies, Peking University. His major research areas are international environment and climate politics, China's environmental diplomacy and international organizations. $\mathrm{He}$ is adviser to the Ministry of Commerce, China, on trade and environment issues; member of the World Economic Forum's Global Agenda Council for Sustainability; and member of the Board of United Nations Association of China. He published more than 50 articles in academic journals at home and abroad. 


\section{Appendices}

Appendix 1. Distribution of socio-demographic information in our sample.
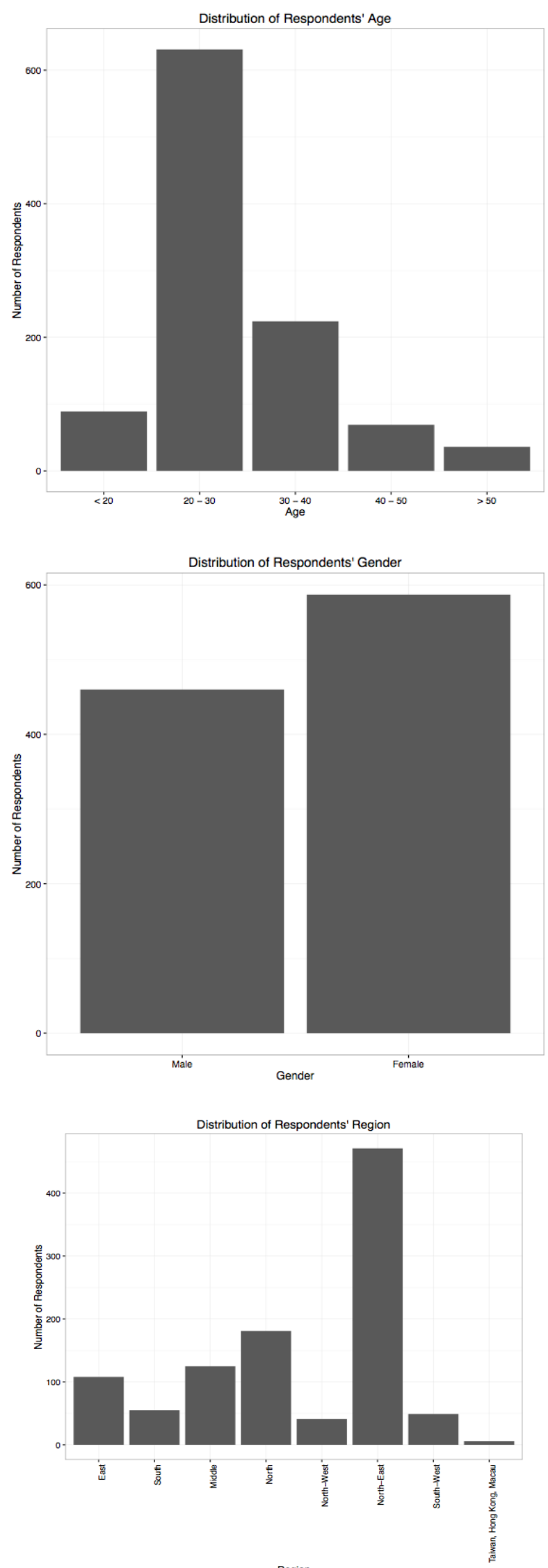

Region 

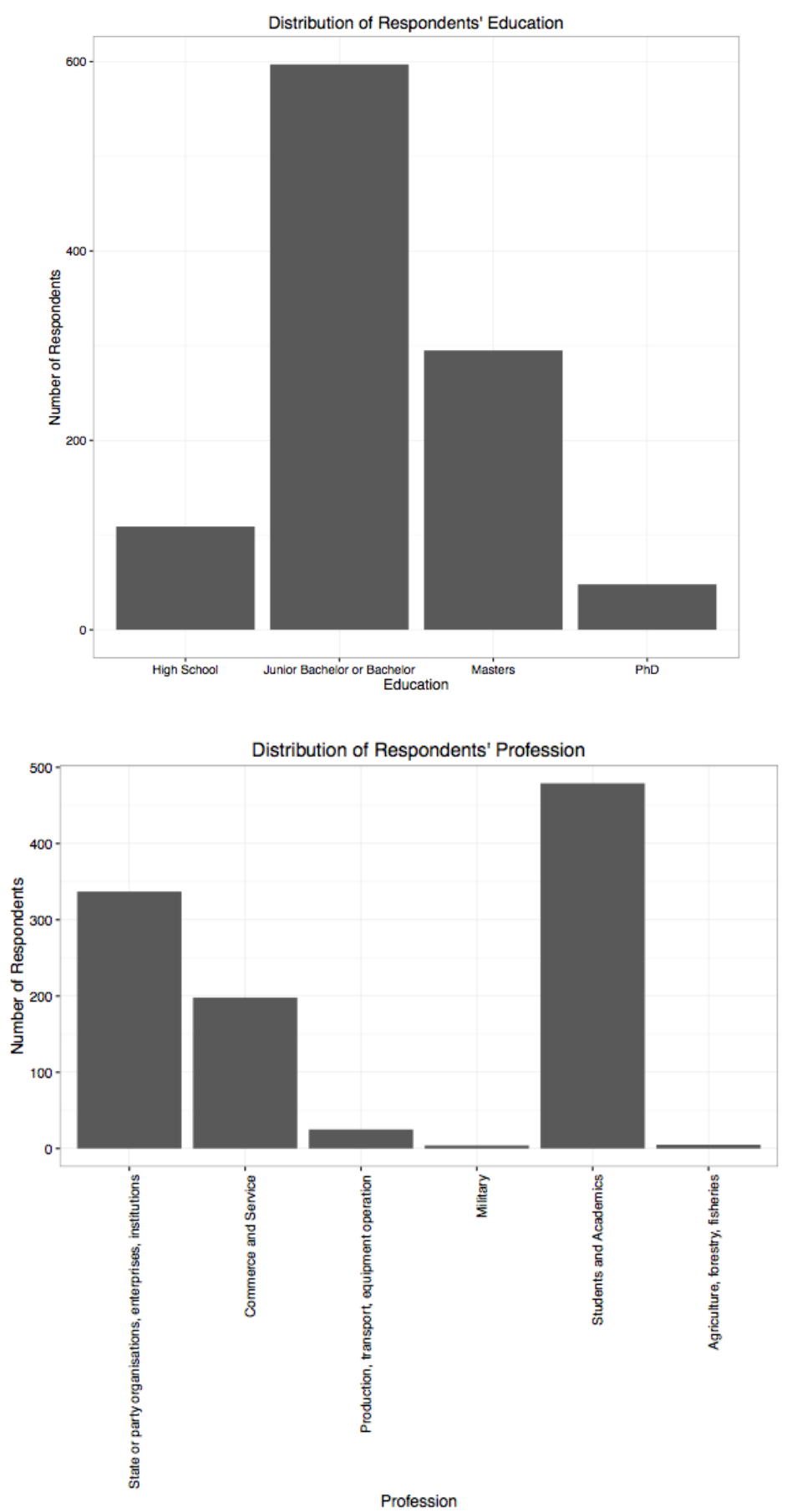
Appendix 2. Distribution of socio-demographic information across treatment conditions.
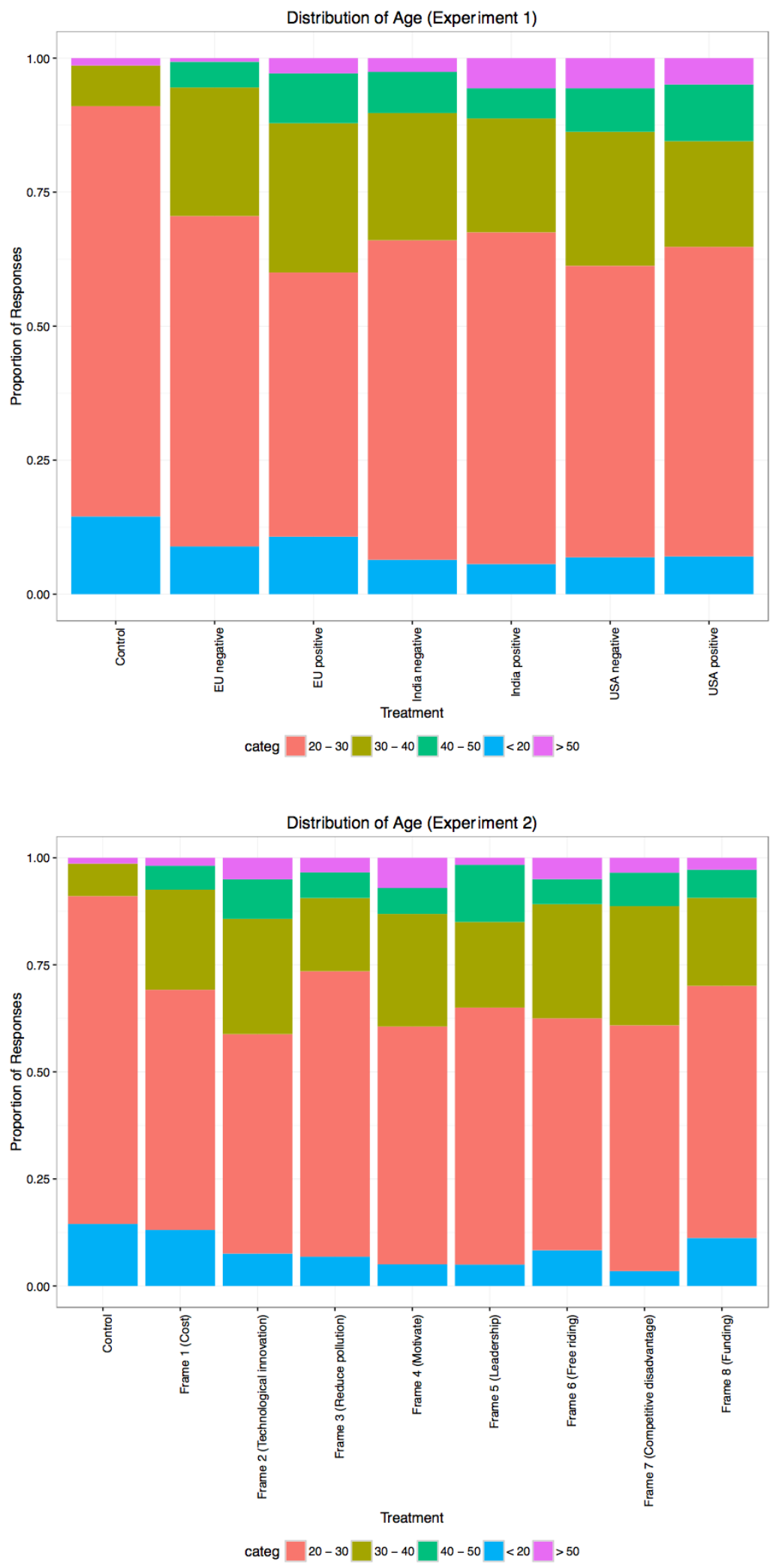

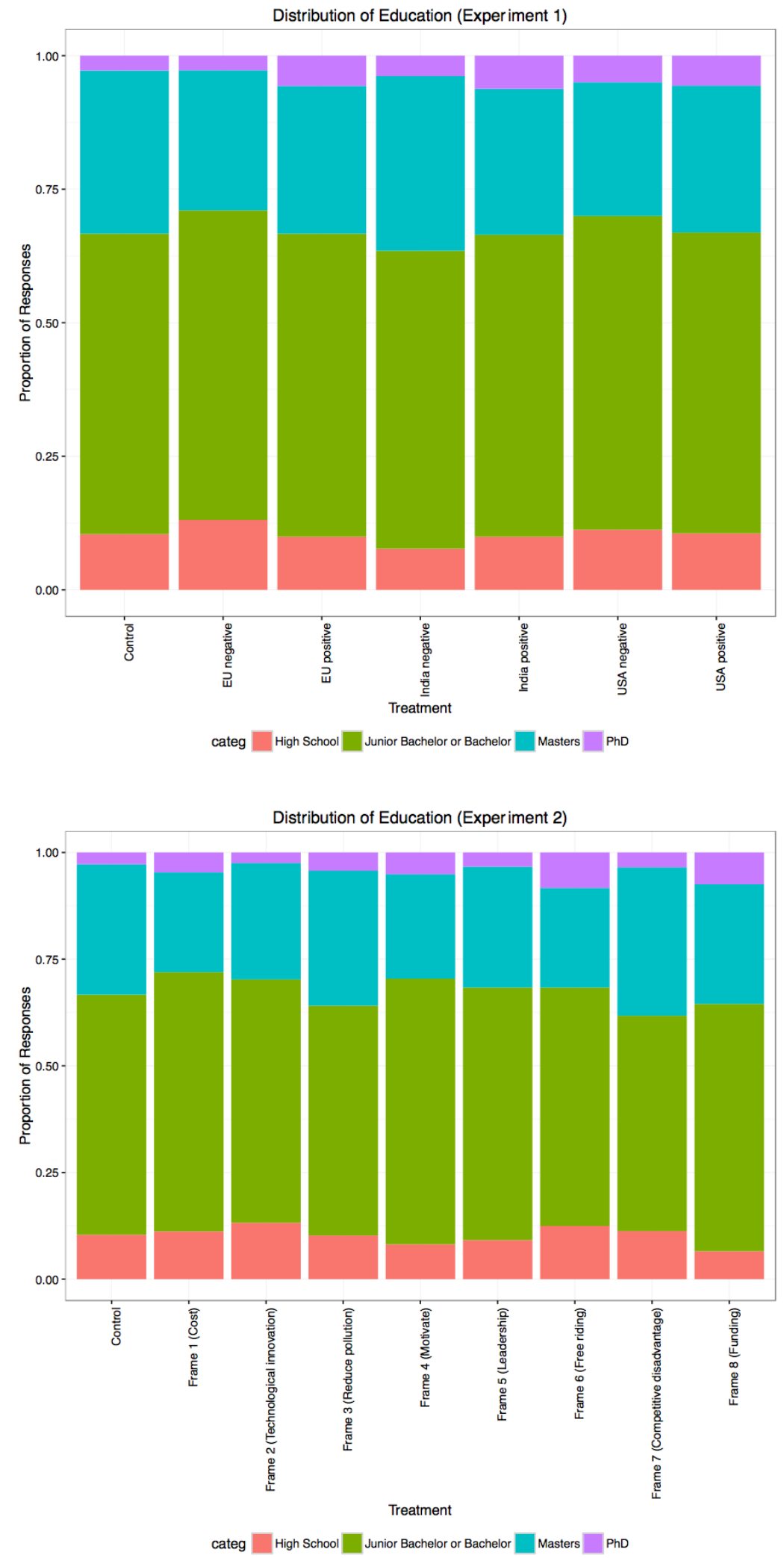

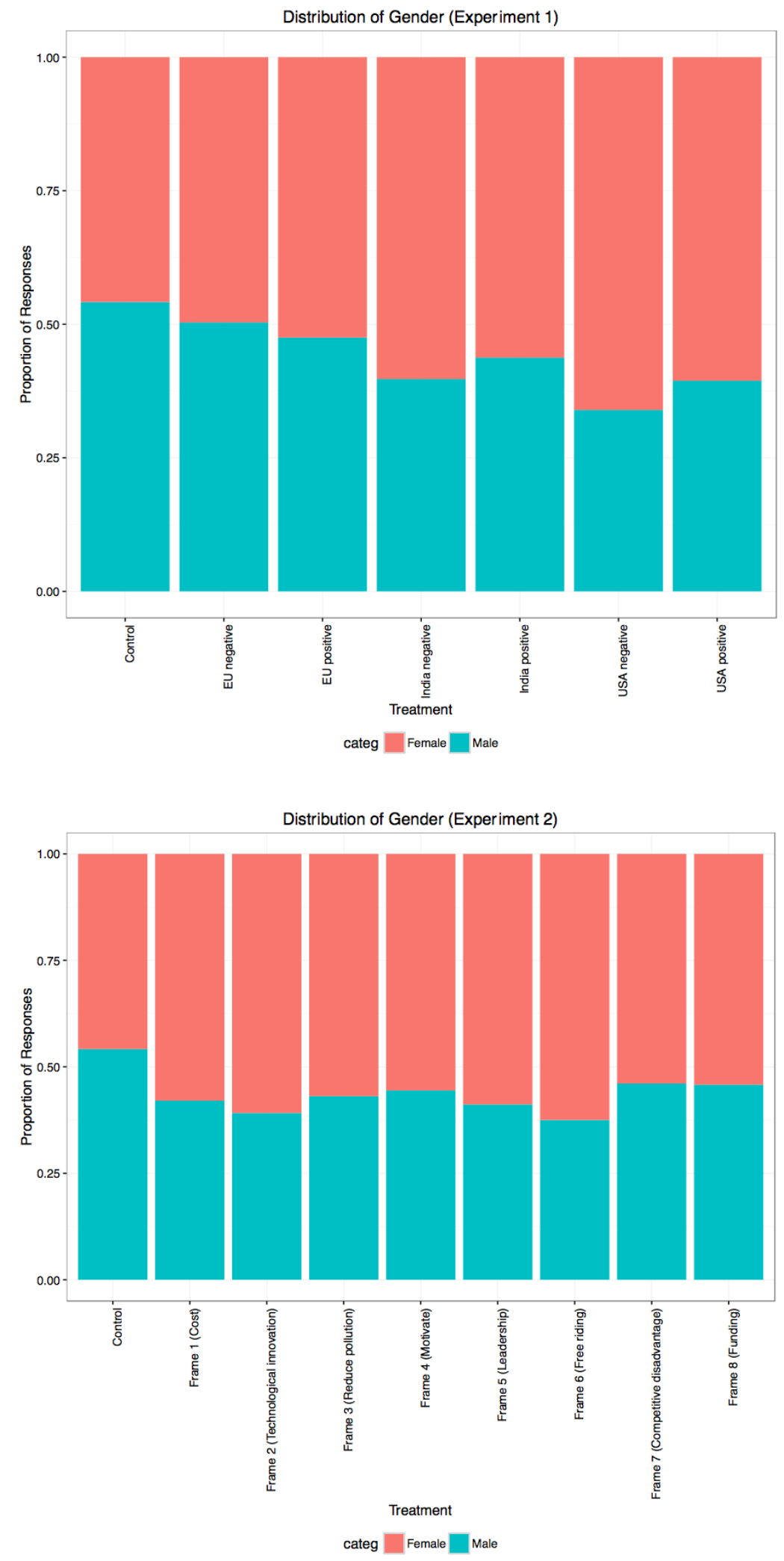

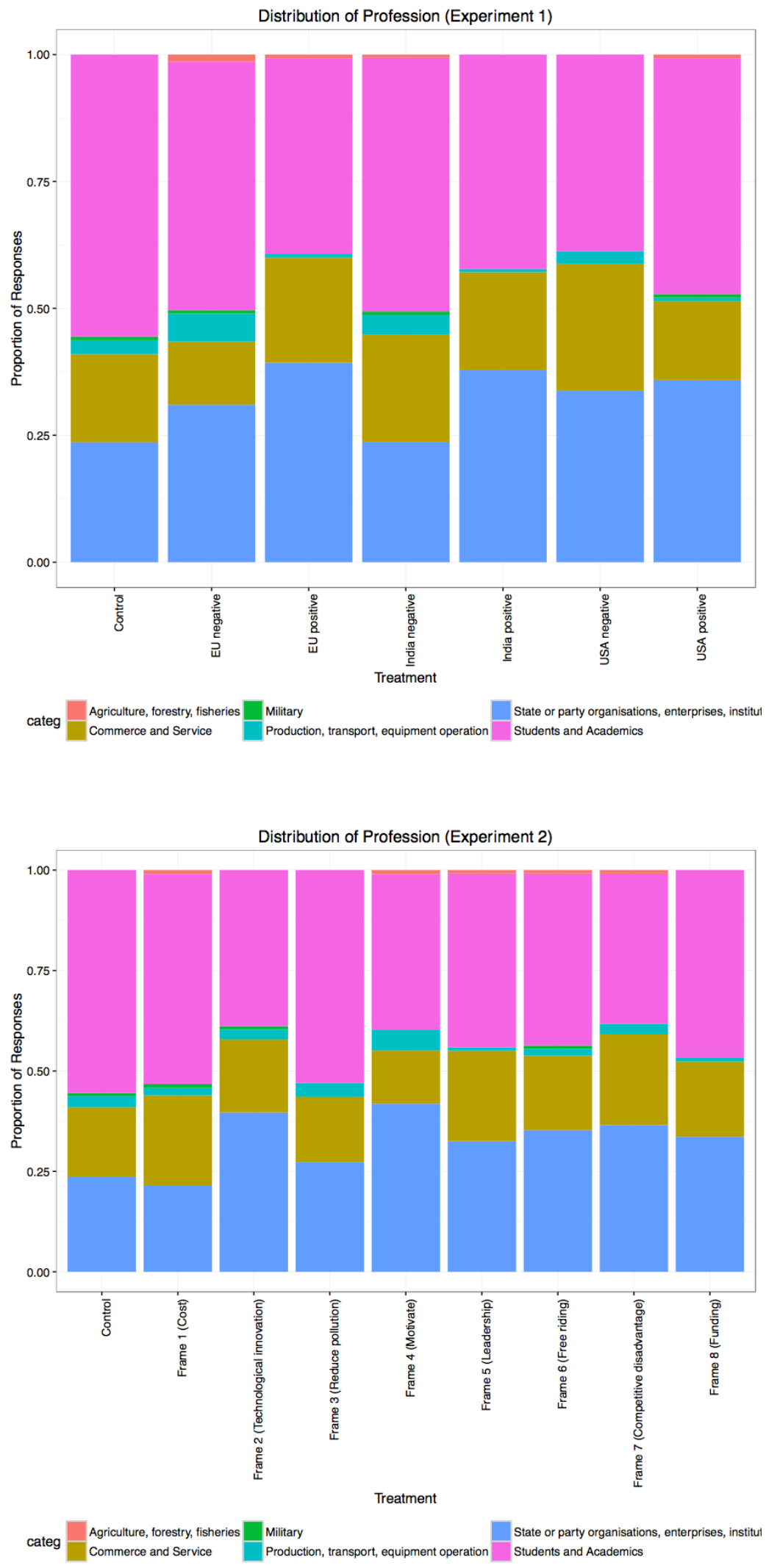

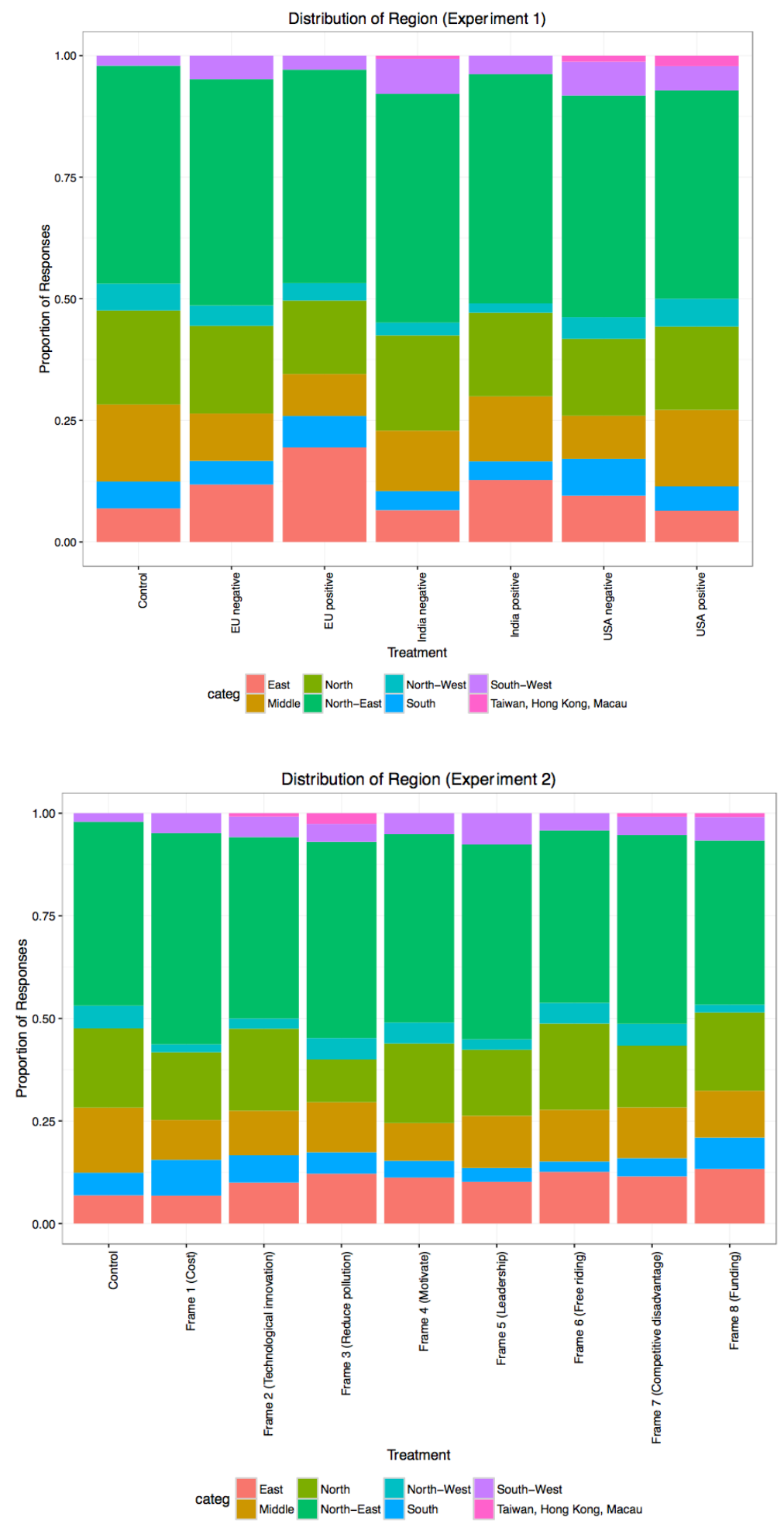


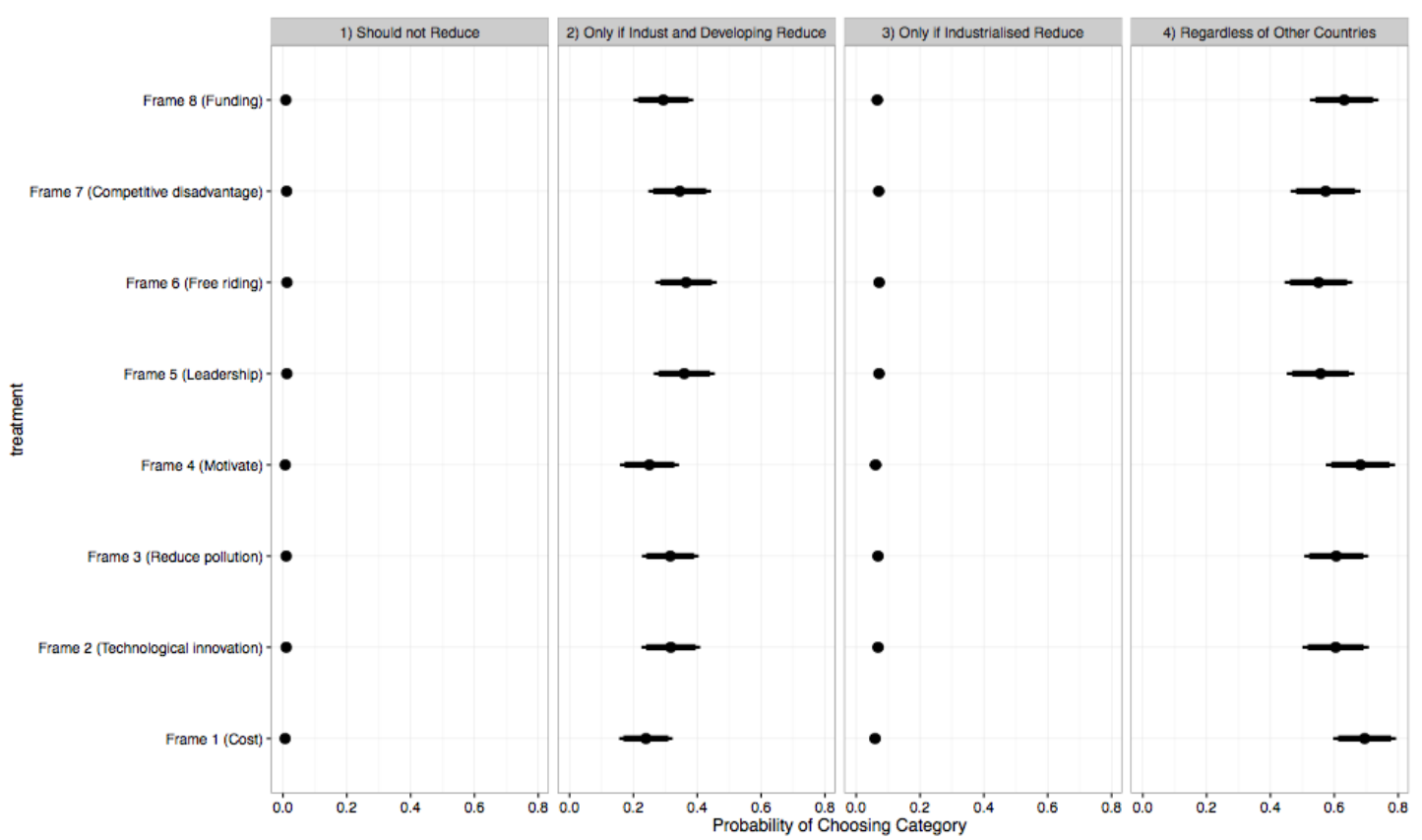

Figure 6. How the probability of response for each category of the outcome measure varies by treatment condition, for experiment 2. Dots indicate point estimates, thick and thin horizontal lines indicate $90 \%$ and $95 \%$ confidence intervals respectively. 